\title{
Antibody-modified iron oxide nanoparticles for efficient magnetic isolation and flow cytometric determination of $L$. pneumophila
}

\author{
Maarten Bloemen - Carla Denis • Miet Peeters • Luc De Meester • \\ Ann Gils • Nick Geukens • Thierry Verbiest
}

Received: 19 February 2015 / Accepted: 23 February 2015

(C) Springer-Verlag Wien 2015

\begin{abstract}
We report on the design of superparamagnetic nanoparticles capable of selectively isolating targeted bacteria (Legionella pneumophila, serogroup 1) from aqueous solutions. The surface of magnetite nanoparticles (NP) was functionalized with a heterobifunctional poly(ethylene glycol) ligand containing reactive groups for covalent coupling of polyclonal antibodies against $L$. pneumophila. These bioconjugates were used to label and magnetically isolate $L$. pneumophila. Flow cytometry revealed high separation and efficiency in this regard. The strain specificity and efficiency of the magnetic NP was tested with recombinant strains of $E$. coli (expressing the red fluorescent protein) and $L$. pneumophila (expressing the green fluorescent protein). The detection limit of the method (by flow cytometry) is $10^{4}$ cells $\mathrm{mL}^{-1}$. The results indicate that the new multifunctional NPs are capable of selectively attracting pathogens from a complex mixture and with high efficiency. This, conceivably, paves the way to pre-concentration protocols for numerous other pathogens.
\end{abstract}

Electronic supplementary material The online version of this article (doi:10.1007/s00604-015-1466-z) contains supplementary material, which is available to authorized users.

\author{
M. Bloemen $(\square) \cdot$ T. Verbiest \\ Department of Chemistry, KU Leuven, Celestijnenlaan 200D, box \\ 2425, 3001 Heverlee, Belgium \\ e-mail: maarten.bloemen@fys.kuleuven.be \\ C. Denis $\cdot$ L. De Meester \\ Department of Biology, KU Leuven, Charles Deberiotstraat 32, Box \\ 2439, 3000 Leuven, Belgium
}

M. Peeters $\cdot$ A. Gils

Department of Pharmaceutical and Pharmacological Sciences, KU

Leuven, O\&N II, Herestraat 49, Box 820, 3000 Leuven, Belgium

N. Geukens

PharmAbs, The KU Leuven Antibody Center, KU Leuven, O\&N II, Herestraat 49, Box 820, 3000 Leuven, Belgium
Keywords Immunomagnetic isolation · Iron oxide · Nanoparticles · Antibodies · Superparamagnetism · Heterobifunctional PEG $\cdot$ Legionella pneumophila

\section{Introduction}

Iron oxide nanoparticles (NP) have become popular since they were applied in fields like magnetic resonance imaging (MRI), hyperthermia or drug delivery carriers.[1-5] For most applications, magnetite $\left(\mathrm{Fe}_{3} \mathrm{O}_{4}\right)$ is the preferred species of iron oxide, because of its interesting magnetic properties.[6] If the NP size ranges between 5 and $25 \mathrm{~nm}$, they exhibit superparamagnetic behavior. This is highly valuable because it combines the large magnetic moment of a ferromagnetic material, with the convenient handling of a paramagnet, which has no net moment without an external magnetic field.[7] Consequently these NP are excellent materials for performing magnetic separation of target ions, molecules or cells from solution.[8, 9] However two more properties of the material are crucial for these applications: their colloidal stability in the medium and their selectivity towards the target. To achieve the first requirement, multiple solutions have been reported. Typically the surface of the NP is coated with a polymer, silica or organic ligands, to introduce functionalities and improve its colloidal properties.[10-12] Recently we reported a strategy to efficiently functionalize the surface of iron oxide nanoparticles with a heterobifunctional poly(ethylene glycol) (PEG) ligand and couple antibodies $(\mathrm{Ab})$ to this layer.[13]

Depending on the target; organic ligands, $\mathrm{Ab}$ or nanobodies with a high affinity can be introduced to acquire selective targeting [9, 14-18]. Xu et al. reported that these NP$\mathrm{Ab}$ bioconjugates can help in the separation of cancer cells from blood.[9] However, to our knowledge, no references are 
present in literature of studies describing a full cell separation study with multiple cell detection techniques. In this manuscript we focus on the magnetic separation of Legionella pneumophila serogroup 1 bacteria from aqueous solutions. These gram-negative bacteria are a wide-spread problem in cooling towers, air-conditioning systems, fountains and showers [19]. They are known to cause the Legionnaires' disease or legionellosis, a serious form of pneumonia [20].

Their detection is mandatory in all publicly accessible water system, like swimming pools, but also in cooling circuits and wastewater. Different methods, such as filtration, centrifugation or immunomagnetic isolation by microparticles, are currently available to separate these bacteria from their aqueous environment for subsequent quantification [21-23]. However all these methods have some specific drawbacks. Filtration has a profound influence on cell viability and centrifugation is less appropriate for large volumes. Moreover these methods are not target specific; so all organisms are retained, including possible inhibitors that might complicate further quantification. Immunomagnetic isolation by microparticles is target specific, but the efficiency is low and cell damage might occur due to the localized excessive magnetic forces [24]. After isolation, quantification of the bacteria can be performed by traditional plate counting or quantitative real-time polymerase chain reactions (qPCR). Even though the culturing method is still considered as the standard, it is very timeconsuming and inconvenient. qPCR is substantially faster but is very susceptible to inhibitors, such as metal salt, surfactants or polysaccharides [25].

In comparison to microparticles, the proposed nanoparticles have a more than 100 times larger surface to volume ratio, which allows binding more Ab to the nanoparticle's surface. Moreover more particles can interact with the cells, resulting in a larger net magnetic moment, hence lowering separation time. On top of that, the magnetic forces are more evenly spread across the cell's surface, which will increase the amount of intact organisms that can be collected.

In this manuscript we report the design of a functionalized iron oxide $\left(\mathrm{Fe}_{3} \mathrm{O}_{4}\right)$ nanoparticle with customized PEG ligands and antibodies. These particles were tested extensively on their ability to specifically attract and separate Legionella pneumophila serogroup 1 bacteria from an aqueous solution. To underline the efficiency, the targeted bacteria were also separated from a mixture of L. pneumophila and Escherichia coli bacteria.

Negative control experiments reported in literature often make use of nanoparticles without a targeting ligand (f.i. an antibody). The recent scientific discussions about protein coronas have shown that the interaction between the nanoparticle's surface and another entity is largely dependent on its coating.[26] Therefor we opted for a negative control composed of iron oxide nanoparticles, conjugated with a nonLegionella targeting antibody (targeting murine PAI-1).

\section{Experimental}

Materials

Allyl-PEG $\mathrm{P}_{10}-\mathrm{OH}$ was obtained from Polysciences, Inc (www. polysciences.com). 2,2-dimethoxy-2-phenylacetophenone (DMPAP, 99 \%), 4-dimethylaminopyridine (DMAP, $99 \%$ ), 1Ethyl-3-(3-dimethylaminopropyl) carbodiimide (EDC), succinic anhydride (99\%) and mercaptopropyltrimethoxysilane (95\%) were purchased from Sigma Aldrich (www.sigmaaldrich.com). N-hydroxy succinimide (98+\%) was purchased from Alfa Aesar (www.alpha.com). Triethylamine was obtained from Janssen Chimica (www.acros.com). 2-(N-morpholino) ethanesulfonic acid monohydrate (MES) was purchased at Fluka (www. sigmaaldrich.com/Fluka). All ultrasonication steps were performed in a Branson 5510 sonicator bath.

\section{Antibody purification}

"New Zealand White" rabbits were immunized with Legionella pneumophila serogroup 1 and murine PAI-1.[27] After collecting the serum, the full IgG fraction was purified using protein A ProSep beads.[28] These polyclonal fractions were used without additional enrichment towards the target protein and denoted as $\mathrm{Ab}$ that target L. pneumophila (pAb $\mathrm{Leg}$ ) and $\mathrm{Ab}$ that target murine PAI-1 ( pAb mur PAI-1; negative control).

Synthesis of the ligands, nanoparticles and functionalization procedure

The heterobifunctional PEG ligand was synthesized as described in our previous report.[13] Allyl-PEG ${ }_{10}-\mathrm{OH}$ (1, $1 \mathrm{eq}$, 4,00 mmol, $1.992 \mathrm{~g}$ ) was mixed with succinic anhydride (1.1 eq, $4.40 \mathrm{mmol}, 440 \mathrm{mg}$ ) and 4-dimethylaminopyridine (DMAP) (0.02 eq, $0.08 \mathrm{mmol}, 9.7 \mathrm{mg}$ ). This mixture was stirred and heated to $50{ }^{\circ} \mathrm{C}$ for 16 hours. The product (2) was purified twice by precipitation in cold diethyl ether, centrifugation and drying in vacuum. ${ }^{1} \mathrm{H}$ NMR $(300 \mathrm{MHz}$, $\mathrm{CDCl}_{3}$ ): $\delta$ (ppm) 2.65 (s, 4H), 3.55-3.75 (m, 38H), 4.02 (d, 2H), $4.26(\mathrm{t}, 2 \mathrm{H}), 5.15-5.32(\mathrm{~m}, 2 \mathrm{H}), 5.85-5.95(\mathrm{~m}, 1 \mathrm{H}) .{ }^{13} \mathrm{C}$ NMR (75 MHz, $\mathrm{CDCl}_{3}$ ): $\delta$ (ppm) 29.2, 29.5, 63.8, 68.9, 69.3, $70.5,72.2,117.1,134.7,172.1$. MS (chemical ionization): $\mathrm{m} / \mathrm{z}=499,101$.

To introduce the siloxane onto the heterobifunctional PEG molecule, allyl-terminated PEG (1 mmol in total, mixture of modified $(0.1 \mathrm{mmol})$ and unmodified $(0.9 \mathrm{mmol}))$ was mixed with (3-mercaptopropyl) trimethoxysilane (1 eq, $1 \mathrm{mmol}$, $185.7 \mu \mathrm{L})$ and 2,2-dimethoxy-2-phenylacetophenone (DMPAP, $0.05 \mathrm{eq}, 0.05 \mathrm{mmol}, 12.8 \mathrm{mg}$ ). This mixture was stirred during 1 hour in a UV reactor, equipped with 3 LEDs (365 nm, output power $200 \mathrm{~mW}$ ). The product (3) was used without further purification. ${ }^{1} \mathrm{H}$ NMR $\left(300 \mathrm{MHz}, \mathrm{CDCl}_{3}\right): \delta$ 
(ppm) $0.76(\mathrm{t}, 2 \mathrm{H}), 1.70(\mathrm{~m}, 2 \mathrm{H}), 1.85(\mathrm{~m}, 2 \mathrm{H}), 2.55(\mathrm{~m}, 4 \mathrm{H})$, $2.64(\mathrm{~s}, 4 \mathrm{H}), 3.57(\mathrm{~s}, 9 \mathrm{H}), 3.55-3.75(\mathrm{~m}, 40 \mathrm{H}), 4.26(\mathrm{t}, 2 \mathrm{H})$.

The synthesis of magnetite NP and coating their surface with siloxanes was performed as described in our previous manuscript.[13, 29] In general, $1 \mathrm{mmol}$ of siloxanes was mixed with $100 \mathrm{mg}$ of $\mathrm{Fe}_{3} \mathrm{O}_{4} \mathrm{NP}$ in $50 \mathrm{~mL}$ of toluene. To this mixture triethylamine $(2.5 \mathrm{~mL})$ and $50 \mu \mathrm{L}$ of water were added. The solution was placed in an ultrasonication bath for 5 hours, after which $50 \mathrm{~mL}$ of heptane was added to precipitate the particles (dispersion becomes turbid). Afterwards, they were attracted magnetically and washed 3 times with acetone. Finally the particles were dried in vacuum and dispersed in MilliQ water (with a concentration up to $20 \mathrm{mg} \mathrm{mL}^{-1}$ ).

\section{Antibody coupling}

The concentrated nanoparticle solution was diluted in $50 \mathrm{mM}$ 2-(N-morpholino)ethanesulfonic acid (MES) buffer, $\mathrm{pH} 5.5$, to reach a final concentration of $3 \mathrm{mg} \mathrm{mL}^{-1} .0 .75 \mathrm{mg} 1$-Ethyl3-(3-dimethylaminopropyl)carbodiimide (EDC) and $0.75 \mathrm{mg}$ N-hydroxysuccinimide (NHS) was added to $1 \mathrm{~mL}$ of this solution and shaken for $20 \mathrm{~min}$ to activate the carboxylic acids. The antibodies $(75 \mu \mathrm{g})$ were diluted in $2 \mathrm{~mL}$ of the same MES buffer after which both solutions were mixed and shaken for 1 hour. To separate the particles from the solution, a Miltenyi Biotech MS magnetic column was used. After rinsing the column with MilliQ water, the nanoparticle dispersion was loaded onto the column, which was placed inside a circular NdFeB magnet. The column was washed 2 times with $1 \mathrm{~mL}$ of sodium phosphate buffer $(20 \mathrm{mM}, \mathrm{pH} 7)$. To elute the particles, the column was removed from the magnet and $0.5 \mathrm{~mL}$ of phosphate buffer and subsequently $0.5 \mathrm{~mL}$ of MilliQ were used as eluents.

\section{Bacterial strains and growth conditions}

Recombinant strains of E. coli and L. pneumophila serogroup 1 expressing the Red Fluorescent Protein (rfp) Green Fluorescent Protein (gfp) genes respectively were used to test strain specificity and efficacy of the iron oxide nanoparticles. The transformed bacteria were cultivated in the presence of appropriate antibiotics $\left(10 \mu \mathrm{g}\right.$ of kanamycin $\mathrm{mL}^{-1}$ for $\mathrm{rfp}$ and $5 \mu \mathrm{g} \mathrm{mL}^{-1}$ chloramphenicol for gfp) to ensure plasmid maintenance. Briefly, Legionella bacteria were cultured by standard procedures at a temperature of $37{ }^{\circ} \mathrm{C}$ on buffered yeast extract agar containing $\alpha$-ketoglutarate (BCYE- $\alpha$ ) supplemented with L-cysteine and ferric pyrophosphate. [30] E. coli bacteria (LMG2092T, rfp labelled and kindly given by Prof. N. Boon, UGent, Belgium) were grown in Luria broth (LB) medium supplemented with kanamycin $\left(10 \mathrm{mg} \mathrm{mL}^{-1}\right)$ and incubated overnight at $30^{\circ} \mathrm{C}$.
Magnetic separation of bacteria

Separate L. pneumophila and E. coli solutions were prepared by spiking Ringer's Solution (Oxoid) with scraped bacteria from the culture plates following the preparation of 10 -fold dilution series. In general, 4 different concentrations of Legionella bacteria (1E7, 1E6, 1E5 and 1E4 cells $\mathrm{mL}^{-1}$ ) were tested in either monospecies suspensions or mixed suspensions with added $E$. coli bacteria. In general, $300 \mu \mathrm{L}$ of each bacteria solution was mixed with $250 \mu \mathrm{L}$ of NP solution ( $0.5 \mathrm{mg} \mathrm{NP})$. Then, this mixture was placed on a rotator at room temperature for 1 hour and afterwards separated by a magnetic column. The supernatant was collected and the column was washed with $1 \mathrm{~mL}$ of MilliQ water. To elute the NP and bacteria, the column was removed from the magnet and $1 \mathrm{~mL}$ of MilliQ was used as an eluent (see Fig. 3b-c).

\section{Flow cytometry}

Cell numbers of L. pneumophila and E. coli were determined by flow cytometry using an Attune ${ }^{\circledR}$ Acoustic Focusing Cytometer (Life Technologies, Gent, Belgium) equipped with a $488 \mathrm{~nm}$ laser, a forward scatter (FSC) diode detector, and a photomultiplier tube (PMT) SSC detector. The instrument was checked for stable fluidic alignment using Performance tracking beads (Life Technologies). Bacterial fractions expressing gfp and rfp fluorescence were detected using, respectively, the BL-1 (530/30 nm) and BL-3 (640 LP) detector. The different fractions of the separation experiment were fixed with $4 \%$ PFA and were diluted 100-fold. The collection rate of the instrument was $25 \mu \mathrm{L} \mathrm{min}{ }^{-1}$ and a total of $50 \mu \mathrm{L}$ was analyzed per sample

\section{Quantitative PCR}

For the specific detection of $L$. pneumophila, a TaqMan qPCR designed by P. Declerck \& J. Behets was used.[31] DNA was extracted using the QIAGEN DNeasy Blood \& Tissue Kit. The primers were based on the macrophage infectivity potentiator (mip) gene and were: LPQF (5'-TTCATTTGYT GYTCGGTTAAAGC) and LPQR (5'-AWTGGCTAAAGG CATGCAAGAC). The mip-specific TaqMan probe was 5' AGCGCCACTCATAG labeled with a 6- carboxyfluorescein (FAM) reporter dye at the $5^{\prime}$ end and a non-fluorescent quencher at the $3^{\prime}$ end. The probe was conjugated to a minor groove binder (MGB) to improve real-time PCR specificity and sensitivity.

\section{Results and discussion}

The procedure to synthesize the nanoparticles was carefully selected for its ability to produce particles at a large scale with 
good monodispersity.[32] Even though these characteristics are not strictly necessary for magnetic separation experiments, it does improve the reproducibility of surface functionalization and antibody coupling. The iron oxide nanoparticles (magnetite, $\mathrm{Fe}_{3} \mathrm{O}_{4}$ ) that were prepared are $8.6 \mathrm{~nm}$ wide in diameter, with a narrow size distribution of $0.6 \mathrm{~nm}$ (see transmission electron microscopy data, Fig. 1). The large scale at which these nanoparticle are produced ( $>10$ grams) ensures that batch-to-batch differences during experiments can be fully excluded.

Even though the functionalization of iron oxides is a wellknown research topic, multiple recent advances have been reported [33]. We choose siloxane surface chemistry in this regard, since it provides the particles with several important properties. First of all, the ligand coating is covalently attached to the surface, which improves its resistance to the environment, merely extreme $\mathrm{pH}$, heat or high ionic strength. Secondly, the ligand can be designed with a specific application in mind. In this case, a PEG backbone was preferred for its excellent solubility in aqueous environments. Moreover, the ligand was altered to have one functional carboxylic acid end-group, which concentration on the nanoparticle can be tailored by mixing with unaltered ligands.

As shown in Fig. 2, the ligand is prepared by a two-step reaction involving an anhydride ring opening reaction and a thiol-ene click chemistry reaction. The latter is very convenient for siloxane chemistry since it occurs fast and without notable side reactions. The product can be used without any further purification, which reduces the chance of crosslinking and hydrolysis of the siloxane group.

The presence of a carboxylic acid group on the ligand implies that $\mathrm{pH}$ will have an influence on the charge of the functionalized nanoparticle. To reduce this potential issue, the modified ligand was mixed with unmodified ligands (siloxane- $\mathrm{PEG}_{10}$ ) during the nanoparticle functionalization

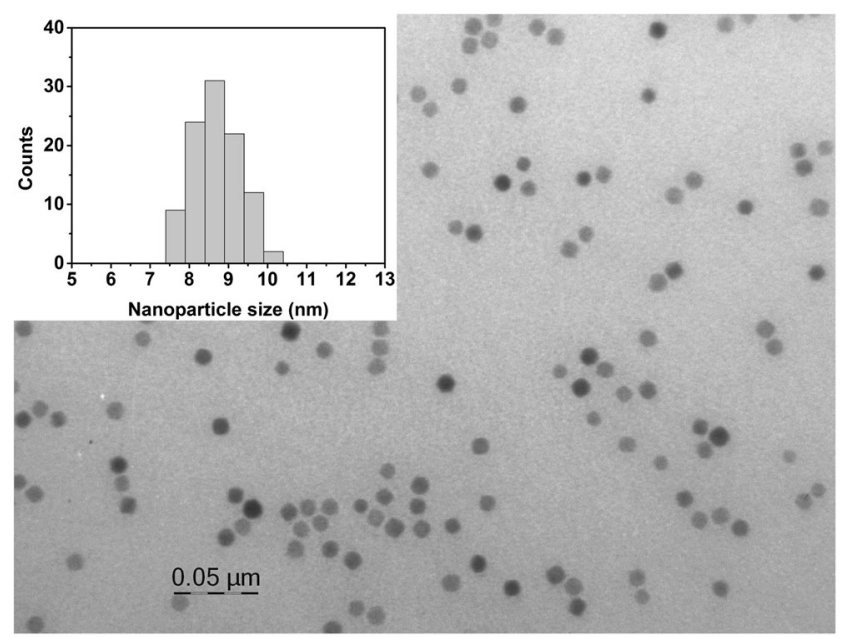

Fig. 1 The synthesized iron oxide (magnetite) nanoparticles are 8.6 \pm $0.6 \mathrm{~nm}$ in size and are spherical procedure. A fixed ratio of $10 \%$ modified to $90 \%$ unmodified ligands was maintained throughout the experiments. Since the subsequent coupling to antibodies will use the present functional groups to form amide bonds, the influence of $\mathrm{pH}$ will be limited, which is necessary to ensure colloidal stability in complex environments (such as buffer solutions).

After functionalization of the nanoparticles' surface, $\mathrm{Ab}$ were covalently coupled onto their carboxylic acid groups. A well-known EDC-NHS approach was preferred for its reproducibility and simplicity.[34] One major drawback of this method is the non-directional bonding that occurs. Since a protein contains multiple free amines, the orientation of the protein can hardly be controlled. Hence a high percentage of the antibodies will lose their activity because of a non-optimal orientation (as shown in Fig. 3a).

The polyclonal antibodies used in this study are the whole IgG fraction of leporine serum, derived from L. pneumophila immunized rabbits. This $\operatorname{IgG}$ usually contains 1 to $5 \%$ of target specific antibodies. It is technically possible to purify this further to a monospecific polyclonal fraction, but this is very time consuming. Moreover, the target species are bacteria, which make the purification even more complex. It would require a column coated with whole $L$. pneumophila bacteria, not just membrane proteins, to ensure that no epitopes would be ignored. Therefore, in this study, the full IgG fraction was used during the coupling experiments, maximizing the range of targeted epitopes. We argue that the gain of having monospecific polyclonal antibodies is small if the bonding is non-directional anyway. A directional (but much more complex) bonding strategy could definitely profit from this on the other hand [34, 35].

The bioconjugated iron oxide nanoparticles were added to monospecies spiked L. pneumophila solutions (1E7, 1E6, 1E5 and $1 \mathrm{E} 4$ cells $\mathrm{mL}^{-1}$ ) and incubated for 1 hour while rotation the test tubes. No precipitation was observed, which is a strong indication that the custom functionalized surface is coping well with the complex environment and is keeping the particle colloidally stable. The dispersion was loaded onto a magnetic column (inside a circular magnet) and the supernatant was collected. After a washing step, the column was removed from the magnet and eluted to collect the nanoparticle-bacteria complexes. This fraction was split to perform all different characterization techniques.

Flow cytometry was selected as the main characterization technique because of its ability to quantify fluorescently labeled bacteria with high accuracy. Since the L. pneumophila strain was labeled with a gfp marker, detection and quantification was straightforward. The results show that as expected the type of antibody, coupled to the nanoparticle, has a profound influence on the magnetic separation behavior. Table 1 shows the amount of bacteria found in the different fractions that were magnetically separated from an initial solution of 5E6 bacteria per milliliter. The presence of antibodies targeting the bacteria clearly has a positive influence on the 

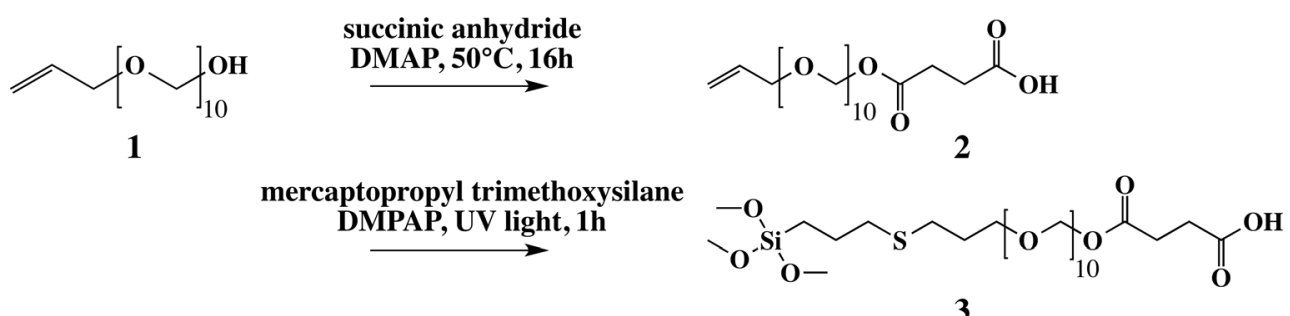

Fig. 2 The allyl-PEG10 molecule is modified first by an anhydride ring opening on the hydroxyl group, resulting in a carboxylic acid group. Secondly the allyl group is used in a thiol-ene click chemistry reaction to attach the siloxane

separation capabilities of the nanoparticles. In the supernatant of the negative control (pAb mur PAI-1), the concentration of cells is more than 150 times higher. While the opposite can be seen in the NP-cell fraction, where the negative control performs more than 10 times worse. Moreover, the final fraction is underestimated by the flow cytometer, since small clusters of bacteria are formed after interaction with nanoparticles. Hence multiple cells are shown as one event only. Experimental data revealed that the underestimation is approximately a factor 2-3 (see Electronic Supplementary Material, Figure S2). The background of the flow cytometer, used in these experiments, is approximately $3 \mathrm{E} 3$ cells $\mathrm{mL}^{-1}$; this number was not subtracted from the experimental values, since this was a systematic error and the influence on the end results is minimal. However, due to this substantial background signal, the limit of detection is limited to $10^{4}$ cells $\mathrm{mL}^{-1}$. Using other quantification techniques can drastically improve this limit of detection. An overview of different purification methods and their respective recoveries can be found in the Electronic Supplementary Material, Table S2. These results show that the nanoparticles are capable of selectively capturing target bacteria from an aqueous solution, even though the antibodies are coupled non-directionally and are not monospecific.
To further underline the capabilities of the functionalized nanoparticles, a separation experiment was performed on a mixed set of bacteria. This would give information about the specificity of the nanoparticles and the behavior of the negative control. In an experiment with only one bacterial species present, the negative control will always detect this bacterium, albeit aspecifically, since no other targets are present. By carefully selecting the two different bacteria (L. pneumophila gfplabeled and $E$. coli rfp-labeled), we were able to discriminate them in the flow cytometry plots and investigate the overall performance. Figure 4 summarizes the data of these experiments. The FCM plots of the supernatants are shown in the left column, while the NP-cell fractions are shown in the right column. The washing steps were omitted for clarity. In the nanoparticle samples coated with pAb Leg (upper row), only a minor presence of L. pneumophila in the supernatant is shown, while a high concentration is present in the NP-cell fraction. E. coli on the other hand stays in the supernatant and is hardly present in the NP-cell fraction. We noticed a small leak of green fluorescence into the red fluorescence detector, which accounts for a significant portion of the visible dots in the red ellipse. Keeping this background in mind, more than 90 percent of the bacteria were successfully separated.

Fig. 3 Schematic overview of the cell separation procedure. First, the functionalized nanoparticles were conjugated to the corresponding antibodies via an amide bond, induced by EDCNHS coupling chemistry (a). Secondly, L. pneumophila solutions were prepared (b), which were brought into contact with the nanoparticles and magnetically separated (c). Finally, the different collected fractions were characterized by flowcytometry and qPCR (d)

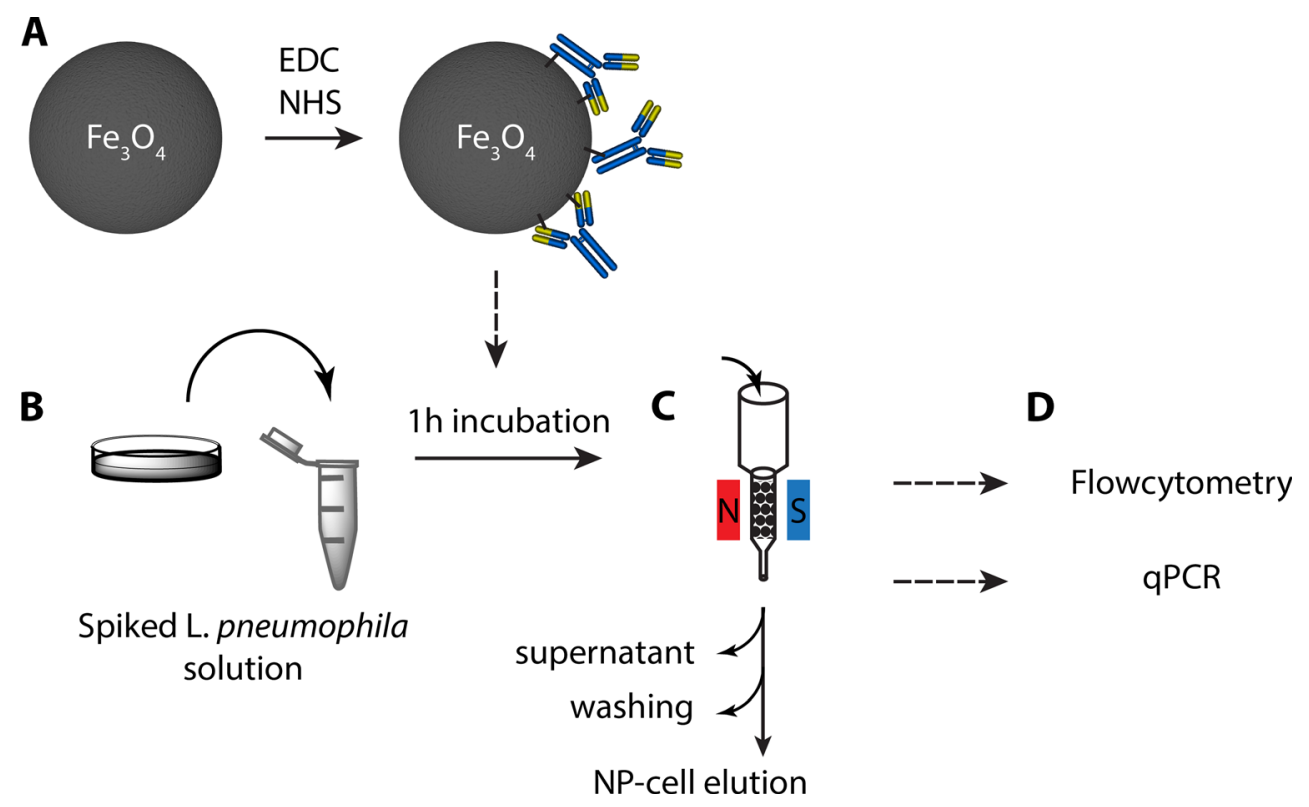


Table 1 The type of antibody has a profound influence on the magnetic separation behavior. This dataset was measured by flow cytometry, based on 3 replicates

\begin{tabular}{llll}
\hline Collected cells mL & Supernatant & Washing step & NP-cell elution \\
\hline NP-pAb Leg & $1.1 \mathrm{E} 4(2.3 \%)$ & $5.0 \mathrm{E} 3(1.1 \%)$ & $4.4 \mathrm{E} 5(96.6 \%)$ \\
NP-pAb mur PAI-1 & $1.9 \mathrm{E} 6(82.7 \%)$ & $3.5 \mathrm{E} 5(15.5 \%)$ & $4.0 \mathrm{E} 4(1.1 \%)$ \\
Ratio & 0.0057 & 0.014 & 11 \\
\hline
\end{tabular}

A large amount of the bacteria is present in the supernatant of the negative control (NP-pAb mur PAI-1), while the final fraction (NP-cell elution) in comparison only contains a few percent. The opposite can be seen for the bioconjugates that target L. pneumophila (NP-pAb Leg): a small number of cells can be found in the supernatant, while a large number is present in the final fraction. The ratio of the two types of conjugates is presented to clarify the difference. The full data set (different concentrations of bacteria: $1 \mathrm{E} 4,2 \mathrm{E} 5,2 \mathrm{E} 6,3 \mathrm{E} 7 \mathrm{cells}_{\mathrm{mL}}^{-1}$ ) can be found in the Electronic Supplementary Material (Table S1)

Nevertheless, this clearly underlines the target-specific magnetic separation that is occurring. In the negative control samples (bottom row), both bacterial species are mainly present in the supernatant, but only minimally in the NP-cell fraction. We can therefore conclude that the negative control nanoparticles only interact aspecifically with the bacteria, as expected.

Fig. 4 The separation capabilities of the nanoparticles are still active in a mixed bacteria environment. L. pneumophila bacteria (gfp-labeled) were mixed with $E$. coli bacteria (rfp-labeled) at a $65 / 35$ ratio $(1.4 \mathrm{E} 5 / 7.4 \mathrm{E} 4$ cells $\left.\mathrm{mL}^{-1}\right)$. The flow cytometry measurements show that the rfplabeled $E$. coli bacteria remain in the supernatant fraction of the pAb Leg coated nanoparticles (upper row), while the $L$. pneumophila bacteria are present in the NP-cell fraction. The negative control nanoparticles (pAb mur PAI-1, bottom row) show a different behavior: both species are visible in the supernatant fraction, with only minor presence in the NP-cell fraction
The presented nanoparticle platform is capable of selectively attracting bacterial species from a complex mixture. Moreover the ligand design is straightforward and thanks to the usage of siloxanes, the ligand is covalently bound to the surface of the NP. Even though the coupling of Ab is non-directional, this did not hamper the properties of the nanoparticles. The selection of polyclonal $\mathrm{Ab}$ as targeting moieties broadened the range of epitopes to which the NP could attach. The magnetic separation strategy strongly reduces the presence of surfactants or metal ions that are present in complex environments, which are known inhibitors for sensitive quantification techniques like qPCR. We believe that this proof of concept can be translated to a wide series of diagnostic applications as a fast and efficient pre-concentration step. Future experiments will optimize the antibody coupling and make use of monospecific $\mathrm{Ab}$ to further enhance the efficiency of the system.

\section{Conclusions}

Superparamagnetic iron oxide nanoparticles were functionalized with a heterobifunctional polyethylene glycol ligand and subsequently bioconjugated with antibodies. The ligand has a

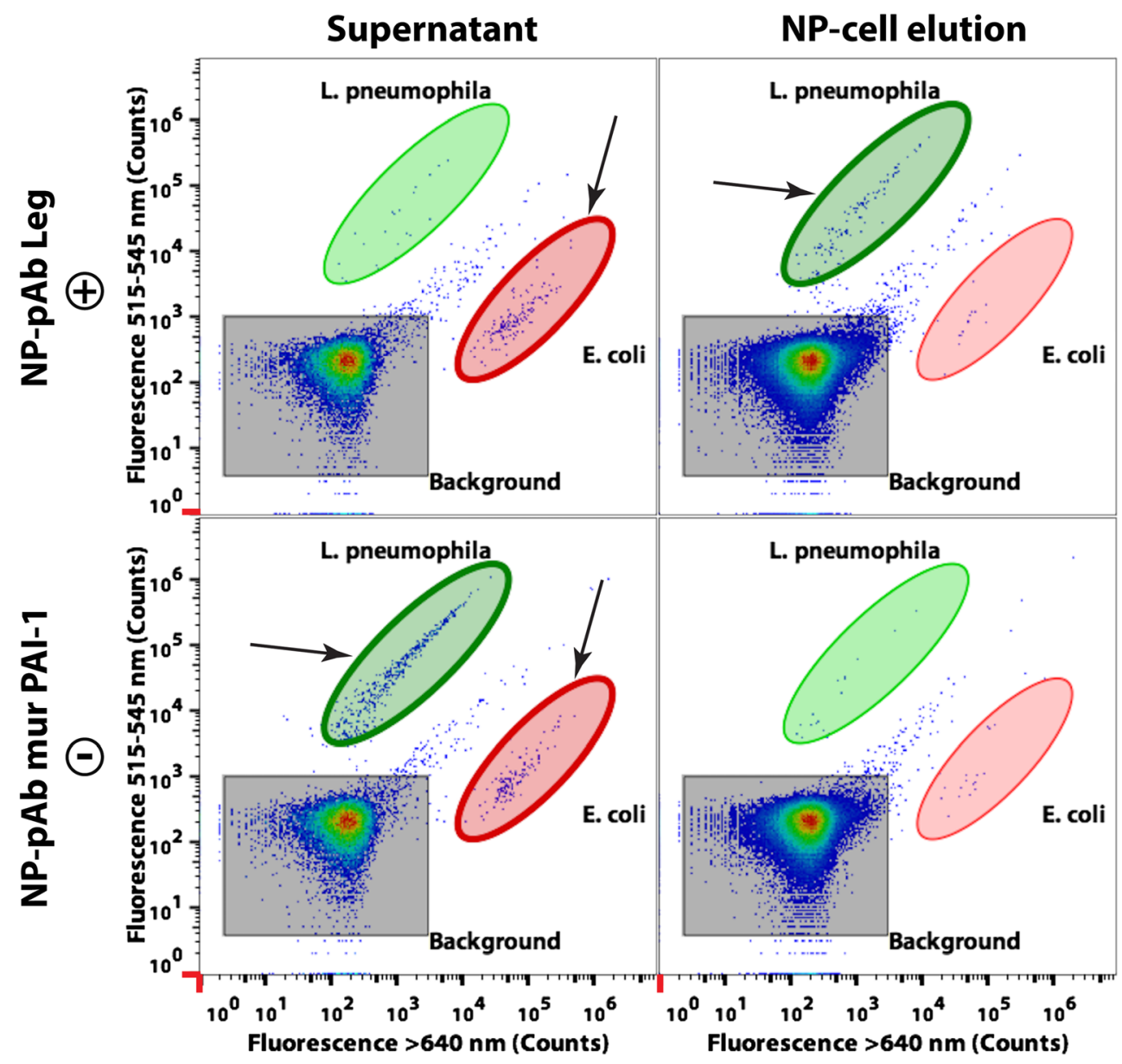


siloxane moiety on one end and one carboxylic group, introduced by an anhydride ring opening, on the other end. We used thiol-ene click chemistry for the siloxane modification, since this type of reactions is fast and gives high yield without side reactions. After surface functionalization of the nanoparticles, antibodies were coupled to the surface. These bioconjugates were added to L. pneumophila bacteria and after magnetic separation, the different fractions were investigated by flow cytometry and qPCR. An enrichment of bacteria was visible in the eluted fraction of the column, showing that the nanoparticles efficiently interact with the targeted species. The negative control showed a more than 10 -fold lower enrichment, caused by aspecific adsorption. Moreover, the targeted species were also attracted from a mixture of bacteria, where a similar enrichment was obtained. These results indicate that the surface functionalized bioconjugates can be used for magnetic separation of bacteria from complex solutions, with great efficiency, even though the antibodies are coupled non-directionally.

Acknowledgments We thank prof. Johan Billen for helping with the TEM measurements. This work was financially supported by grant G.0618.11 N of the Fund for scientific research Flanders (FWO-V) and the Agency for Innovation by Science and Technology in Flanders (IWT). M. Bloemen is grateful for support from the IWT.

Conflict of interest The authors declare that they have no conflict of interest.

Compliance with ethical standards All legal and ethical requirements for the welfare of animals were met by the Animalium Department of the KU Leuven.

\section{References}

1. Lartigue L, Innocenti C, Kalaivani T, Awwad A, Sanchez Duque MDM, Guari Y, Larionova J, Guérin C, Montero JLG, BarraganMontero V, Arosio P, Lascialfari A, Gatteschi D, Sangregorio C (2011) Water-dispersible sugar-coated iron oxide nanoparticles. an evaluation of their relaxometric and magnetic hyperthermia properties. J Am Chem Soc 133:10459

2. Larson TA, Bankson J, Aaron J, Sokolov K (2007) Hybrid plasmonic magnetic nanoparticles as molecular specific agents for MRI/optical imaging and photothermal therapy of cancer cells. Nanotechnology $18: 325101$

3. Babes L, Denizot B, Tanguy G, Le Jeune JJ, Jallet P (1999) Synthesis of iron oxide nanoparticles used as MRI contrast agents: a parametric study. J Colloid Interface Sci 212:474

4. Mahon E, Salvati A, Baldelli Bombelli F, Lynch I, Dawson KA (2012) Designing the nanoparticle-biomolecule interface for "targeting and therapeutic delivery". J Control Release 161:164

5. Kim J, Kim HS, Lee N, Kim t, Kim H, Yu T, Song IC, Moon WK, Hyeon T (2008) Multifunctional uniform nanoparticles composed of a magnetite nanocrystal core and a mesoporous silica shell for magnetic resonance and fluorescence imaging and for drug delivery. Angew Chem Int Ed Engl 47:8438
6. Brullot W, Reddy NK, Wouters J, Valev VK, Goderis B, Vermant J, Verbiest T (2012) Versatile ferrofluids based on polyethylene glycol coated iron oxide nanoparticles. J Magn Magn Mater 324:1919

7. Bedanta S, Kleemann W (2009) Supermagnetism. J Phys D Appl Phys 42:013001

8. Shahbazi-Gahrouei D, Abdolahi M, Zarkesh-Esfahani SH, Laurent S, Sermeus C, Gruettner C (2013) Functionalized magnetic nanoparticles for the detection and quantitative analysis of cell surface antigen. Biomed Res Int 2013:349408

9. Xu H, Aguilar ZP, Yang L, Kuang M, Duan H, Xiong Y, Wei H, Wang A (2011) Antibody conjugated magnetic iron oxide nanoparticles for cancer cell separation in fresh whole blood. Biomaterials 32: 9758

10. Na HB, Palui G, Rosenberg JT, Ji X, Grant SC, Mattoussi H (2012) Multidentate catechol-based polyethylene glycol oligomers provide enhanced stability and biocompatibility to iron oxide nanoparticles. ACS Nano 6:389

11. Petri-Fink A, Steitz B, Finka A, Salaklang J, Hofmann H (2008) Effect of cell media on polymer coated superparamagnetic iron oxide nanoparticles (SPIONs): colloidal stability, cytotoxicity, and cellular uptake studies. Eur J Pharm Biopharm 68:129

12. Ji X, Shao R, Elliott AM, Stafford RJ, Esparza-Coss E, Bankson JA, Liang G, Luo ZP, Park K, Markert JT, Li C (2007) Bifunctional gold nanoshells with a superparamagnetic iron oxide-silica core suitable for both $\mathrm{mr}$ imaging and photothermal therapy. J Phys Chem C Nanomater Interf 111:6245

13. Bloemen M, Van Stappen T, Willot P, Lammertyn J, Koeckelberghs G, Geukens N, Gils A, Verbiest T (2014) Heterobifunctional PEG ligands for bioconjugation reactions on iron oxide nanoparticles. PLoS One 9:e109475

14. Koh I, Wang X, Varughese B, Isaacs L, Ehrman SH, English DS (2006) Magnetic iron oxide nanoparticles for biorecognition: evaluation of surface coverage and activity. J Phys Chem B 110:1553

15. Dupont D, Brullot W, Bloemen M, Verbiest T, Binnemans K (2014) Selective uptake of rare earths from aqueous solutions by EDTAfunctionalized magnetic and nonmagnetic nanoparticles. ACS Appl Mater Interfaces 6:4980

16. Horák D, Babic M, Macková H, Benes MJ (2007) Preparation and properties of magnetic nano- and microsized particles for biological and environmental separations. J Sep Sci 30:1751

17. Chalmers JJ, Xiong Y, Jin X, Shao M, Tong X, Farag S, Zborowski M (2010) Quantification of non-specific binding of magnetic microand nanoparticles using cell tracking velocimetry: Implication for magnetic cell separation and detection. Biotechnol Bioeng 105:1078

18. Chalasani R, Vasudevan S (2012) Cyclodextrin functionalized magnetic iron oxide nanocrystals: a host-carrier for magnetic separation of non-polar molecules and arsenic from aqueous media. J Mater Chem 22:14925

19. Atlas RM (1999) Legionella: from environmental habitats to disease pathology, detection and control. Environ Microbiol 1:283

20. Vogel JP, Isberg RR (1999) Cell biology of Legionella pneumophila. Curr Opin Microbiol 2:30-34

21. Behets J, Seghi F, Declerck P, Verelst L, Duvivier L, Van Damme A, Ollevier F (2003) Detection of Naegleria spp. and Naegleria fowleri: a comparison of flagellation tests, ELISA and PCR. Water Sci Technol 47:117

22. Behets J, Declerck P, Delaedt Y, Creemers B, Ollevier F (2006) Quantitative detection and differentiation of free-living amoeba species using SYBR green-based real-time PCR melting curve analysis. Curr Microbiol 53:506

23. Pernin P, Pélandakis M, Rouby YA (1998) Comparative recoveries of Naegleria fowleri amoebae from seeded river water by filtration and centrifugation. Appl Environ Microbiol 64:955

24. Yáñez MA, Carrasco-Serrano C, Barberá VM, Catalán V (2005) Quantitative detection of Legionella pneumophila in water samples 
by immunomagnetic purification and real-time PCR amplification of the dotA gene. Appl Environ Microbiol 71:3433

25. Demeke T, Jenkins GR (2010) Influence of DNA extraction methods, PCR inhibitors and quantification methods on real-time PCR assay of biotechnology-derived traits. Anal Bioanal Chem 396:1977

26. Lundqvist M, Stigler J, Elia G, Lynch I, Verdervall T, Dawson KA (2008) Nanoparticle size and surface properties determine the protein corona with possible implications for biological impacts. Proc Natl Acad Sci U S A 105:14265

27. Van De Craen B, Scroyen I, Vranckx C, Compernolle G, Lijnen HR, Declerck PJ, Gils A (2012) Maximal PAI-1 inhibition in vivo requires neutralizing antibodies that recognize and inhibit glycosylated PAI-1. Thromb Res 129:e126

28. Van Stappen T, Brouwers E, Tops S, Geukens N, Vermeire S, Declerck PJ, Gils A (2014) Generation of a highly specific monoclonal anti-infliximab antibody for harmonization of TNF-coated infliximab assays. Ther Drug Monit. Just Accepted

29. Bloemen M, Brullot W, Luong TT, Geukens N, Gils A, Verbiest T (2012) Improved functionalization of oleic acid-coated iron oxide nanoparticles for biomedical applications. J Nanoparticle Res 14: 1100

30. Köhler R, Bubert A, Goebel W, Steinert M, Hacker J, Bubert B (2000) Expression and use of the green fluorescent protein as a reporter system in Legionella pneumophila. MGG - Mol Gen Genet 262:1060

31. Behets J, Declerck P, Delaedt Y, Creemers B, Ollevier F (2007) Development and evaluation of a Taqman duplex real-time PCR quantification method for reliable enumeration of Legionella pneumophila in water samples. J Microbiol Methods 68:137

32. Park J, An K, Hwang Y, Park JG, Noh HJ, Kim JY, Park JH, Hwang NM, Hyeon T (2004) Ultra-large-scale syntheses of monodisperse nanocrystals. Nat Mater 3:891

33. Schladt TD, Schneider K, Schild H, Tremel W (2011) Synthesis and bio-functionalization of magnetic nanoparticles for medical diagnosis and treatment. Dalt Trans 40:6315

34. Hermanson G (2008) Bioconjugate techniques, 2nd ed. 1202

35. Rao SV, Anderson KW, Bachas LG (1998) Oriented immobilization of proteins. Mikrochim Acta 128:127 